\title{
Column classification and selection for the determination of antibiotics by micellar liquid chromatography
}

\author{
M. Rambla Alegre, S. Carda-Broch, J. Esteve-Romero* \\ Àrea de Química Analítica, Departament de Química Física i Analítica, Universitat Jaume I, 12071 \\ Castelló, Spain \\ * Correspondence: josep.esteve@qfa.uji.es
}

\begin{abstract}
Seven commercially available: Zorbax $\mathrm{C}_{18}$, Kromasil $\mathrm{C}_{18}, \mathrm{C}_{8}$, cyano, phenyl, monolithic and amino stationary phases columns, have been characterized and classified into broadly similar types to simplify column choice. The results were evaluated employing cluster analysis, which shows several interesting groups based on distances (Minkowski and Euclidean) in agreement with the manufacturer's claims: chain density of the stationary phase used, and the presence or not a silica base. Finally, results showed that $\mathrm{C}_{18}$ columns offer the best chromatographic characteristics for separation and quantification of antibiotics in micellar liquid chromatography.
\end{abstract}

Keywords: Amoxicillin; Norfloxacin; SDS; Micellar mobile phase; Dendrogram; Cluster Analysis 


\section{INTRODUCTION}

\section{Column selection}

Column selection in reversed-phase liquid chromatography is still not a straightforward process. The increasing number of commercially available reversed phases with which experienced analysts are faced can cause dilemmas when it comes to column selection. The problem is further complicated by the fact that the manufactures do not use a standardised testing procedure.

The differences that exist among commercially available reversed-phase highperformance liquid chromatographic stationary phases are considerable and have attracted our interest from both the theoretical and the practical point of view. The chromatographic differences that are observed between similarly prepared columns are due to differences in the characteristics of the material used as a support and in the technique used to form the bonding phase.

Many manufacturers provide physical parameters (Table 1) related to their packing materials, such as percent carbon load, particle size $(\mu \mathrm{m})$, distribution, surface area $\left(\mathrm{m}^{2} / \mathrm{g}\right)$, pore size $(\AA)$, pore volume $(\mathrm{mL} / \mathrm{g})$, calculated bonded phase coverage $\left(\mu \mathrm{mol} / \mathrm{m}^{2}\right)$ and whether the phase has been end-capped or not. These physical properties are essential in determining column efficiency and retention. Therefore, for the synthesis of well-defined and reproducible reversed high-performance liquid chromatography (RHPLC) phases these properties must be known since, if properly controlled, they are extremely useful for quality control purposes. However, there is often little correlation between these parameters and the chromatographic performance of the phase. ${ }^{[1-3]}$ 
Octadecylsilyl (ODS) bonded-phase silica $\left(\mathrm{C}_{18}\right)$ is the most widely used stationary phase for reversed-phase high-performance liquid chromatography. Another choice could be columns with shorter alkyl ligands, which are made from the same silica but with shorter-chain alkyl $\left(\mathrm{C}_{8}\right)$.

A major constraint of silica-bonded phases is their limited $\mathrm{pH}$ range. Zorbax Extend$\mathrm{C}_{18}$ columns incorporate a patented bidentate organosilane combined with double endcapping to protect their ultra-pure silica support from dissolution at high $\mathrm{pH}$ (up to 11.5). The bonded stationary phase is non-polar in nature and it is specially designed for stable use with high $\mathrm{pH}$ mobile phases to obtain stable separation with excellent peak shapes and column efficiency.

Monolithic columns are made out of the same starting material as conventional particulate silica high-performance liquid chromatography (HPLC) materials, i.e. ultra pure silanes. Hence, having very high mechanical stability and an ability to work at higher flow rates might be useful to speed up these chromatographic methods.

In a chromatographic system, the phenyl phase undergoes $\pi$ - $\pi$ interaction between the $\pi$-electrons of the stationary phase and the solute. ${ }^{[4]}$ Synder et al. ${ }^{[5]}$ have reported that phenyl phases possess an increased polarity and a hydrophobicity that is lower than that of alkyl bonded phases; they also have lower shape selectivity, which may be attributed to their lower ligand concentration. To sum up, phenyl columns have a high retention character because of their highly aromatic nature and also due to their spatial circumstances, since the molecules are planar and this allows stronger retention to be achieved through $\pi-\pi$ interaction.

While developing a separation method for polar compounds, aqueous mobile phases must be used and these can collapse the octyl or octadecyl alkyl chain that is commonly used. This can lead to poor retention and selectivity as well as poor reproducibility. A polar stationary phase, such as amine bonded to silica, can be used to address this 
problem. ${ }^{[6,7]}$ This stationary phase retains polar compounds longer than non-polar compounds and the polar mobile phase, water, is a strong solvent. Amino columns offer a more reactive stationary phase in comparison to alkyl phases. Lack of protection of the stationary phase surface from the mobile phase could lead to dissolution of the packing, particularly at higher $\mathrm{pH}$ values.

Cyano columns are less commonly used, in part because of concerns about their stability ${ }^{[8]}$ and reproducibility. ${ }^{[9]}$ A common observation is that cyano columns are less retentive (i.e. more polar), much less hydrophobic and less sterically restricted, and have lower hydrogen-bond acidity than alkyl bonded columns. This unusual behavior can be attributed to strong interactions between the polar head group of the surfactant and the cyano group of the polar bonded phase due to the fact that the carbon atom of the cyano possesses no directly bonded hydrogen atoms. Cyano columns show an effect known as antibinding behaviour. This occurs with compounds that have the same charge as the surfactant and is a direct result of a compound being driven into the stationary phase as the micelle content of the mobile phase is increased because the compound is excluded, not only from the micelle, but also from the double layer that surrounds the micelle. In comparison, antibinding behaviour does not occur in alkyl bonded columns.

\section{Tanaka protocol}

Nowadays, different chromatographic parameters based on the Tanaka protocol ${ }^{[10]}$ are used in characterisation procedures (Table 2). These column parameters are the retention factor for pentylbenzene $\left(\mathrm{k}_{\mathrm{PB}}\right)$, which reflects the surface area and surface coverage (ligand density): hydrophobic selectivity $\left(\alpha_{\mathrm{CH} 2}\right)$, which is the retention factor ratio between n-pentylbenzene $(\mathrm{PB})$ and n-butylbenzene $(\mathrm{BB})$ and measurement of the surface coverage: shape selectivity $\left(\alpha_{\mathrm{T} / \mathrm{O}}\right)$ is a measure of the number of available silanol 
groups and the degree of endcapping: hydrogen bonding capacity $\left(\alpha_{C / P}\right)$ is a measure of the number of available silanol groups and the degree of endcapping: total ion exchange capacity $\left(\alpha_{\mathrm{B} / \mathrm{P}} \mathrm{pH}\right.$ 7.6) is an estimate of the total silanol activity: and acidic ion exchange capacity $\left(\alpha_{\mathrm{B} / \mathrm{P}} \mathrm{pH} 2.7\right)$ is a measure of the acidic activity of the silanol groups.

\section{Micellar liquid chromatography}

Micellar liquid chromatography (MLC) is a chromatographic technique that uses surfactants as part of the mobile phase composition at a concentration higher than the critical micellar concentration (cmc). In MLC, anionic sodium dodecyl sulphate, or SDS, is the most widely used surfactant and a wide range of solutes with different polarities can be separated in the same run without the requirement of gradient elution. This is achieved due to the differential association of the solutes between the micelles in the mobile phase, and to the stationary phase, which is modified by the adsorption of monomers of surfactant. ${ }^{[11]}$

In MLC, surfactant molecules readily adsorb in bonded stationary phases. Because many stationary phase properties are altered by the process of surfactant adsorption, ${ }^{[12]}$ the modification of the stationary phase by adsorbed surfactant can have profound implications with regard to retention and selectivity in MLC. It is a combination of the interaction of the micelles and the surfactant-modified stationary phase with the solute that defines the selectivity of the separation.

A simplified model of the SDS-modified $\mathrm{C}_{18}$ bonded stationary phase has also been used by Armstrong and Berthod ${ }^{[13]}$ to explain poor stationary phase mass transfer in MLC. The hydrophobic alkyl tail of the surfactant SDS appears to be associated with the alkyl bonded phase, with the sulphate group oriented away from it. ${ }^{[1]}$ Thus, projecting its polar head group away from the bonded phase towards the mobile phase 
would greatly affect the polarity of the bonded phase and would also lead to the formation of an anionic hydrophilic layer, which would explain the superior resolution achieved by SDS for hydrophilic compounds. The increased polarity of the alkyl bonded phase as a result of SDS adsorption is evident. Consequently, shorter retention times of compounds are obtained.

Armstrong and Henry ${ }^{[14]}$ demonstrated that micelles can be used in place of traditional organic modifiers, such as methanol or acetonitrile, in RPLC. Micelles, which are dynamic assemblies of surfactant molecules, can organise and compartmentalise solutes at various sites within the surfactant assembly. Retention in MLC has been shown to be correlated to surfactant type and the concentration of surfactant in the mobile phase. ${ }^{[11,15]}$ Solute retention in MLC generally decreases with increasing surfactant concentration, but the rate of decrease can vary considerably from one solute to another.

Many of the advantages offered by micellar mobile phases, e.g. simultaneous separation of charged and neutral compounds, the ability to directly inject biological material into the column without prior sample work-up, and so forth, are due to the unique ability of micelles to organise and compartmentalise solutes at the molecular level. However, surfactant molecules are readily adsorbed in hydrocarbonaceous stationary phases. Since many properties of HPLC stationary phases are altered by the process of surfactant adsorption, the modification of the bonded stationary phase by adsorbed surfactant molecules can have profound implications with regard to retention and selectivity in MLC.

Using micellar mobile phases containing SDS as the surfactant, the retention time of compounds is longer in $\mathrm{C}_{8}$ than in $\mathrm{C}_{18}$, even though the $\mathrm{C}_{18}$ phase has a higher carbon loading. This can probably be attributed to lower SDS sorption in octylsilane because of the higher bonding chain density of the $\mathrm{C}_{8}$ phase used in this study. ${ }^{[16]}$ Lower SDS 
sorption would result in a more hydrophobic (less polar) phase. Since the hydrophilic layer formed by sorbed SDS is responsible for the superior resolution, the decrease in the resolution occurs when a $\mathrm{C}_{8}$ column is used.

Several chromatographic tests can be found in the literature to characterise reversedphase columns ${ }^{[17-24]}$ and are already applied in laboratory practice, while others are still under development. Our method affords an opportunity to examine the properties of stationary phases, such as column efficiency, hydrophobicity, retention times and asymmetry. In order to compare and contrast a range of well-established stationary phases, we performed a column characterisation approach in MLC. The chromatographic approach was combined with differing chemometric approach tools, such as cluster analysis.

\section{EXPERIMENTAL}

\section{Materials and Reagents}

Amoxicillin ( $\alpha$-amino- $p$-hydroxybenzyl-penicillin) is an aminopenicillin with a broad spectrum, and it is currently the most commonly used antibiotic. Chemically, amoxicillin has a $\log P_{o / w}=0.87$ and its dissociation constants are $\log K=2.4$, 7.4, 9.6. [25] Amoxicillin is used orally to treat lower respiratory tract infections, otitis media, sinusitis, skin and skin structure infections, and urinary tract infections. On the other hand, norfloxacin (1-ethyl-6-fluoro-1,4-dihydro-4-oxo-7-(1-piperazinyl)-3-quinolonecaboxylic acid) is a synthetic broad-spectrum quinolone anti-infective agent. Chemically, it is a basic ( $\log \mathrm{K}=6.26$ and $\log K=8.85$ ) and highly hydrophobic compound $\left(\log P_{o / w}=1.25\right)$, and its principal physiological action is bactericidal. ${ }^{[25]}$ These antibiotics are good models for assessing the scope and applicability of the 
characterisation procedure in the rational selection of stationary phases using clustering analysis. Structures are shown in Figure 1.

\section{Chromatographic Conditions}

In order to select the best stationary phase for a simple separation that includes the two antibiotics, seven commercially available stationary phases: alkyl, $\mathrm{C}_{18}$ or $\mathrm{C}_{8}$, zorbax, cyano, phenyl or monolithic, and amino were characterized characterised to classify columns into broadly similar types, thus simplifying column choice in micellar liquid chromatography. All of them were $150 \mathrm{~mm}$ (length) x $4.6 \mathrm{~mm}$ (i.d.) with a particle size of $5 \mu \mathrm{m}$, except for the Chromolith- $\mathrm{C}_{18}$, which was $100 \mathrm{~mm}$ long.

The chromatographic system was an Agilent Technologies Series 1100 (Palo Alto, CA, USA), equipped with a quaternary pump, an autosampler and a diode array and fluorescence detectors (range 190-700 nm). Detection was performed using the UV unit at $210 \mathrm{~nm}$ for amoxicillin and the fluorescence unit at $230 \mathrm{~nm}$ (excitation) and $312 \mathrm{~nm}$ (emission) for norfloxacin. Columns were thermostatted at $20^{\circ} \mathrm{C}$. The flow rate and injection volume were $1 \mathrm{~mL} / \mathrm{min}$ and $20 \mu \mathrm{L}$, respectively. Analytes were typically eluted within $30 \mathrm{~min}$ in the entire test. The signal was acquired by a personal computer connected to the chromatograph by means of a Hewlett Packard Chemstation (Rev. A.10.01).

Micellar mobile phases containing $0.05,0.10,0.15$ and $0.20 \mathrm{M}$ of SDS were prepared and used at $\mathrm{pH} 3$ and 7. The first disturbance of the baseline on the injection of methanol was used as the dead time marker. 


\section{RESULTS AND DISCUSSION}

\section{Clustering analysis used as chemometric tool}

The most widely used method for pattern recognition in chemometrics is cluster analysis. ${ }^{[26]}$ Cluster analysis is the collective name for several techniques that are able to partition objects or variables into different groups. The most widely used are hierarchical clustering methods. Cluster analysis is used to classify objects so that similar objects are grouped together and dissimilar objects are found in different groups. The starting point is always a data table in which objects (columns in our case) are described by several characteristics. They produce a classification in such way that any small cluster of a partition is fully included in one of the bigger clusters of the consecutive partition. Before one starts the partition of $n$ objects or variables it is necessary to determine the similarity between all objects. The Euclidean distance (considered to be the shortest distance between two points in two dimensions), which is a measure of the geometric distance in a multidimensional space, is determined for each pair of objects. The correlation coefficient between variables is more frequently used when clustering the variables, but the Minkowski distance (the generalised distance between two points) is the most commonly used measure of distance when using ratio scales (when there is an absolute zero). The results are normally represented graphically by a dendrogram (a diagram in which the most similar objects are linked together first).

Clustering Analysis was performed using SPSS 14.0 software (SPSS Inc. Headquarters, Chicago, Illinois), which contains a statistical pack that allows this kind of mathematical analysis to be conducted. All variables from the column characterisation were included in the analysis (Table 2). In order to give all variables the same importance, they were autoscaled, i.e. the average was subtracted from each 
variable and each variable was divided by its standard deviation. The tabulated data were sufficient to identify wide differences, although more subtle differences may have been overlooked. In the present instance the (dis)similarity is based on Euclidean distance and Minkowski distance, since the eventual aim is to select/assess the best column within a range of commercially available columns for use in Micellar Liquid Chromatography.

\section{Dendrogram}

By applying the clustering method to the autoscaled data, with the Euclidean and Minkowski distances as the measure of (dis)similarity, two dendrograms were obtained that show the similarity between seven commercially available alkyl phases, based on the experimental parameters. The same dendrogram was obtained using the Euclidean and Minkowski distances.

The dendrogram (Fig. 2) shows several interesting groupings based on a rescaled distance below 3 , for example, $\mathrm{C}_{18}$ and zorbax columns were grouped together, which is in agreement with the manufacturer's claims. The same conclusions are obtained for $\mathrm{C}_{8}$ and monolithic columns, which could be attributed to lower SDS sorption because of the higher bonding chain density of the stationary phase used. Amino and phenyl columns are in the same dendrogram group due to the fact that both display similar characteristics (\% C load). Finally, the most different is the cyano column, which shows low selectivity for both these compounds and also low efficiency.

Furthermore, there are three cluster groups based on a distance below 7 . The first consists of $\mathrm{C}_{18}$, Zorbax, $\mathrm{C}_{8}$ and monolithic columns. This group shows similar selectivity because the stationary phase contains a silica base. No silica-based columns 
(amino, phenyl and cyano) are situated outside the silica-based cluster group due to the bonding nature and \% $\mathrm{C}$ load.

It can be observed that the best results are obtained with the $\mathrm{C}_{18}$ column, as shown in the chromatogram (Fig. 3a), which shows adequate analysis time and good efficiencies. The $\mathrm{C}_{8}$ column shows intermediate results, with high efficiencies but a very long analysis time (Fig. 3b). Finally, the column that was seen to offer the poorest results in this analysis was the cyano column (Fig. 3c).

Finally, the $\mathrm{C}_{18}$ column was selected as the best for separation. In a chromatographic system with micellar mobile phases, $\mathrm{C}_{18}$ columns are the most widely used and best suited to analysing most drugs and pharmaceutical compounds. Most research papers describe the use of a $\mathrm{C}_{18}$ column. In this work, eight columns were compared, the conclusion being that $\mathrm{C}_{18}$ offers the best chromatographic characteristics. Our research group and other groups have developed studies and applications using MLC of different compounds and the $\mathrm{C}_{18}$ column has been utilised in most of them. Compounds such as vitamins, ${ }^{[27]}$ corticosteroids, ${ }^{[28]}$ anticonvulsants, ${ }^{[29,30]}$ barbiturates, ${ }^{[31]}$ stimulants, ${ }^{[32]}$ antihistamines,${ }^{[33]}$ phenetylamines, ${ }^{[34]}$ sulphonamides, ${ }^{[35-}$ 37] diuretics, ${ }^{[38,39]}$ benzodiazepines, ${ }^{[40]}$ quinolonas, ${ }^{[41]}$ as well as other drug compounds ${ }^{[42]}$ and applications for screening analysis ${ }^{[43]}$ have been studied. 


\section{CONCLUSION}

The systematic chemometric analysis of chromatographic data with the use of complementary techniques such as clustering makes it possible to uncover the information present in the data. MLC has proved to be a useful technique in the analysis of diverse groups of substances. One of the main advantages that MLC offers is the possibility of determining drugs in complex matrices without any pretreatment. MLC uses mobile phases that are non-toxic, non-flammable, biodegradable and relatively inexpensive in comparison to other methods. Seven columns were tested, and results showed that $\mathrm{C}_{18}$ columns offer the best chromatographic characteristics for separation.

Surfactant-bonded phase interactions in MLC are very important. A fundamental understanding of these interactions is crucial to develop separations with greater selectivity in MLC. Hence, finding the appropriate combination of surfactant and stationary phase is crucial in micelle-mediated separations. $\mathrm{C}_{18}$ columns have proved to be the most suitable for MLC.

\section{ACKNOWLEDGEMENTS}

This study was part of Projects CTQ2007-64473/BQU and P1-1B2006-12 funded by MEC and Fundació Caixa Castelló-Bancaixa-Universitat Jaume I, respectively. Maria Rambla-Alegre thanks also MEC for FPU grant. 


\section{REFERENCES}

1. Euerby M. R., Petersson P. Chromatographic classification and comparison of commercially available reversed-phase liquid chromatographic columns using principal component analysis. J. Chromatogr. A. 2003, 994, 13-36.

2. Neue U.D., Serowik E., Iraneta P., Alde B.A., Walter T.H. Universal procedure for the assessment of the reproducibility and the classification of silica-based reversedphase packings I. Assessment of the reproducibility of reversed-phase packings. J. Chromatogr. A. 1999, 849, 87-100.

3. Olsen B.A., Sullivan G.R. Chemometric categorization of octadecylsilyl bondedphase silica columns using test mixtures and confirmation of results with pharmaceutical compounds separation. J. Chromatogr. A. 1995, 692, 147-159.

4. Brindele R.R., Albert K., Stationary phases with chemically bonded fluorine ligands: A new approach for inevironmental analysis of $\pi$-electron containing solutes. J. Chromatogr. A. 1997, 757, 3-20.

5. Marchand D.H., Croes K., Dolan J.W., Snyder L.R., Henry R.A., Kallury K.M.R., Waite S., Carr P.W. Column selectivity in reversed-phase liquid chromatography VIII. Phenylalkyl and fluoro-subtituted columns. J. Chromatogr. A. 2005, 1062, 6578.

6. Layne J. Characterization and comparison of the chromatographic performance of conventional, polar-embedded, and polar-endcapped reversed-phase liquid chromatography stationary phases. J. Chromatogr. A. 2002, 957, 149-164.

7. McCalleu D.V. Comparison of the perfonmance of conventional C18 phases with others of alternative functionality for the analysis of basic compounds by reversedphase high-performance liquid chromatography. J. Chromatogr. A. 1999, 844, 2338. 
8. Okusa K., Tanaka H., Ohira M. Development of a new cyano-bonded column for high-performance liquid chromatography. J. Chromatogr. A. 2000, 869, 143-149.

9. Smith R.M., Miller S.I. Comparison of the selectivity of cyano-bonded silica stationary phases in phase liquid chromatography. J. Chromatogr. 1989, 464, $297-$ 306.

10. Petersson P., Euerby M.R., An evaluation of the robustness of the Tanaka characterization protocol for reversed-phase liquid chromatography columns. J. Sep Sci. 2005, 28(16), 2120-2129.

11. Berthod A., García-Alvarez-Coque C., Micellar Liquid Chromatography, MarcelDekker, New York, 2000.

12. Berthod A., Roussel A., The role of the stationary phase in micellar liquid chromatography. Adsorption and efficiency. J. Chromatogr. 1988, 449, 349-360.

13. Armstrong D.W., Ward T.J., Berthod A., Effects on Molecular Diffusion: Theoretical and chromatographic Considerations. Anal. Chem. 1986, 58, 579-582.

14. Armstrong D.W., Henry S.J. Use of an aqueous micellar mobile phase of separation of phenols and polynuclear aromatic hydrocarbons via HPLC. J. Liq. Chromatog. 1980, 3, 657-662.

15. Lavine B.K., Hendayana S., Tetreault J. Selectivity in micellar reversed-phase liquid chromatography: C18 and C8 alkyl bonded phases. Anal. Chem. 1994, 66, $3458-3465$.

16. Berthod A., Girard I., Gonnet C. Micellar Liquid Chromatography. Adsorption Isotonic Surfactants on Five Stationary Phases. Anal. Chem 1986, 58, 1356-1361.

17. Lavine B.K., Hendayana S., Cooper W.T., He Y. Selectivity in micellar liquid chromatography: surfactant bonded phase interactions. I. C-18. J. Liq. Chrom. \& Rel. Technol. 1997, 20(3), 351-376. 
18. Lavine B.K., Hendayana S., Cooper W.T., He Y. Selectivity in micellar liquid chromatography: Surfactant bonded phase interactions. II. C-8 and Cyanopropyl. J. Liq. Chrom. \& Rel. Technol. 1997, 20(3), 377-402.

19. Marchand D.H., Croes K., Dolan J.W., Snyder L.R. Column selectivity in reversedphase liquid chromatography. VII. Cyanopropyl columns. J. Chromatogr. A. 2005, $1062,57-64$.

20. Euerby M.R., Petersson P., Campbell W., Roe W. Chromatographic classification and comparison of commercially available reversed-phase liquid chromatographic columns containing phenyl moieties using principal component analysis. J. Chromatogr. A. 2007, 1154, 138-151.

21. Cruz E., Euerby M.R., Johnson C.M., Hackett C.A. Chromatographic classification of commercially available reverse-phase HPLC columns. Chromatographia. 1997, $44,151-161$

22. Euerby M.R., Patersson P. Chromatographic classification and comparison of commercially available reversed-phase liquid chromatographic columns containing polar embedded groups/amino endcappings using principal component analysis. J. Chromatogr. A. 2005, 1088, 1-15.

23. Detroyer A., Schoonjans V., Questier F., Vander Heyden Y., Borosy A.P., Guo Q., Massart D.L., Exploratory chemometric analysis of the classification of pharmaceutical substances based on chromatographic data. J. Chromatogr. A. 2000, 897, 23-26.

24. Olsen B.A. Hydrophilic interaction chromatography using amino and silica columns for the determination of polar pharmaceuticals and impurities. J. Chromatogr. A. 2001, 913, 113-122.

25. Clarke's Analysis of Drugs and Poisons, Pharmaceutical Press, London (UK), 2004. 
26. Massart D.L., Smeyers-Verbeke J., Vander Heyden Y. Classifying chromatographic systems by clustering. LCGC Europe, Feb. 2006.

27. Monferrer Pons Ll., Gil Agustí M., Capella Peiró M.E., Esteve Romero J. Micellar liquid chromatography determination of $\mathrm{B}$ vitamins with direct injection and ultraviolet absorbance detection. J. Chromatogr. A. 2003, 984, 223-231.

28. Capella Peiró M.E., Gil Agustí M., Monferrer Pons Ll., Esteve Romero J. Direct injection micellar liquid chromatographic method for the analysis of corticosteroids in creams, ointments and other pharmaceuticals. Anal. Chim. Acta. 2002, 454: 125135.

29. Martinavarro A., Capella Peiró M.E., Gil Agustí M., Marcos Tomás J.V., Esteve Romero J. Therapeutic drug monitoring of anticonvulsant drugs by micellar hplc with direct injection of serum samples. Clinical Chemistry. 2002, 48, 1696-1702.

30. Gil Agustí M., Carda Broch S., Alvarez Coque M.C.G., Esteve Romero J. Micellar liquid chromatographic determination of anti-convulsant drugs in pills and capsules. J. Liq. Chrom Rel. Technol. 2000, 23(9), 1387-1401.

31. Capella Peiró M.E., Gil Agustí M., Martinavarro Dominguez A., Esteve Romero J. Determination in serum of some barbiturates using micellar liquid chromatography with direct injection. Analytical Biochem. 2002, 309, 261-268.

32. Gil Agustí M., Capella Peiró M.E., Martinavarro Domínguez A., Esteve Romero J., Chromatographia. Determination of some banned stimulants in sports by micellar liquid chromatography. 2003, 57,51-57.

33. Gil Agustí M., Alvarez Coque M.C.G., Esteve Romero J. Correlation between hydrophobicity and retention data of several antihistamines in reversed-phase liquid chromatography with aqueous-organic and micellar-organic mobile phases. Anal. Chim. Acta. 2000, 421:, 45-55. 
34. Gil Agustí M., Torres Lapasió J.R., Alvarez Coque M.C.G., Esteve Romero J. Comparison of the performance of butanol and pentanol as modifiers in the micellar chromatographic determination of some phenethylamines. J. Chromatogr. A. 2000, $866,35-49$.

35. Alvarez Coque M.C.G., Simó E.F., Ramis Ramos G., Esteve Romero J. Highperformance micellar liquid chromatography determination of sulphonamides in pharmaceuticals after azodye precolumn derivatization. J. Pharm. \& Biomed. Anal. 1995, 13, 237-245.

36. Raviolo M.A., Rambla Alegre M., Clausell Tornos J., Capella Peiró M.E., Carda Broch S., Esteve Romero J. Determination of sulfonamides in milk after precolumn derivatisation by micellar liquid chromatography. Anal. Chim. Acta. 2007, 593, 152-156.

37. Simó Alfonso E.F., Ramis Ramos G., Alvarez Coque M.C.G. Determination of sulphonamides in human urine by azo dye precolumn derivatization and micellar liquid chromatography. J. Chromatorg. B. 1995, 670, 183-187.

38. Carda Broch S., Alvarez Coque M.C.G., Simó Alfonso E.F., Esteve Romero J. Micellar liquid chromatographic determination of diuretics by diazotization and coupling with the Bratton-Marshall reagent. Anal. Chim. Acta. 1997, 353, 215-226.

39. Ruiz Angel M.J., Torres Lapasió J.R., Garcia Alvarez Coque M.C. Effects of pH and the presence of micelles on the resolution of diuretics by reversed-phase liquid chromatography. J. Chromatogr. A. 2004, 1022, 51-65.

40. Capella Peiró M.E., Bose D., Gil Agustí M., Esteve Romero J. Direct injection micellar liquid chromatographic determination of benzodiazepines in serum. J. Chromatogr. B: Biomed. Appl. 2002, 780, 241-249. 
41. Vílchez J.L., Araujo L., Prieto A., Navalón A. Determination of ciprofloxacin and enoxacin in human serum samples by micellar liquid chromatography. Anal. Chimica Acta. 2004, 516, 135-140.

42. Esteve Romero J., Carda Broch S., Gil Agustí M., Capella Peiró M.E., Bose D. Micellar liquid chromatography for the determination of drug materials in pharmaceuticals preparations and biological samples. TRAC 2005, Vol. 24 (2), 7591.

43. Ruiz Angel M.J., Caballero R.D., Simó Alfonso E.F., Garcia Alvarez Coque M.C. Micellar liquid chromatography: suitable technique for screening analysis. J. Chromatogr. A. 2002, 947, 31-45. 
A

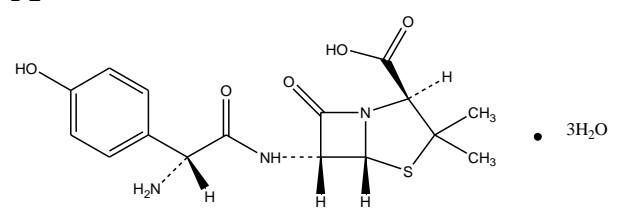

B<smiles>CCC1CC(CC)c2cc(C)ccc2C1=O</smiles>

Figure 1. Structures of amoxicillin (A) and norfloxacin (B). 
Rescaled Distance Cluster Combine

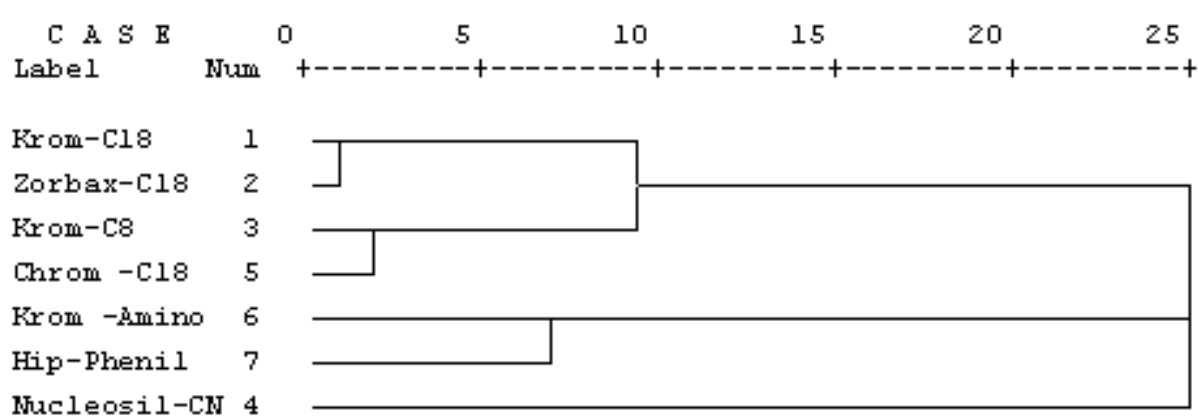

Figure 2. Dendrogram using Centroid Method and Hierarchical Cluster Analysis. 


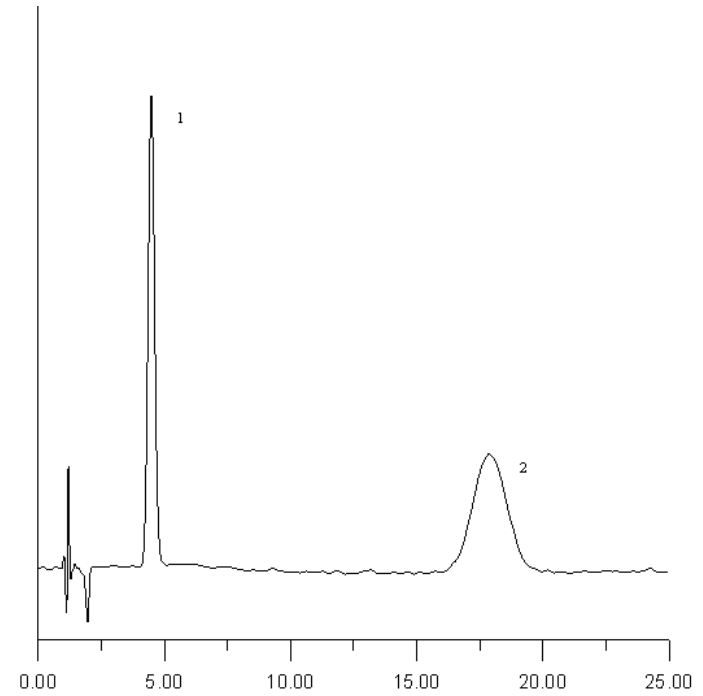

b

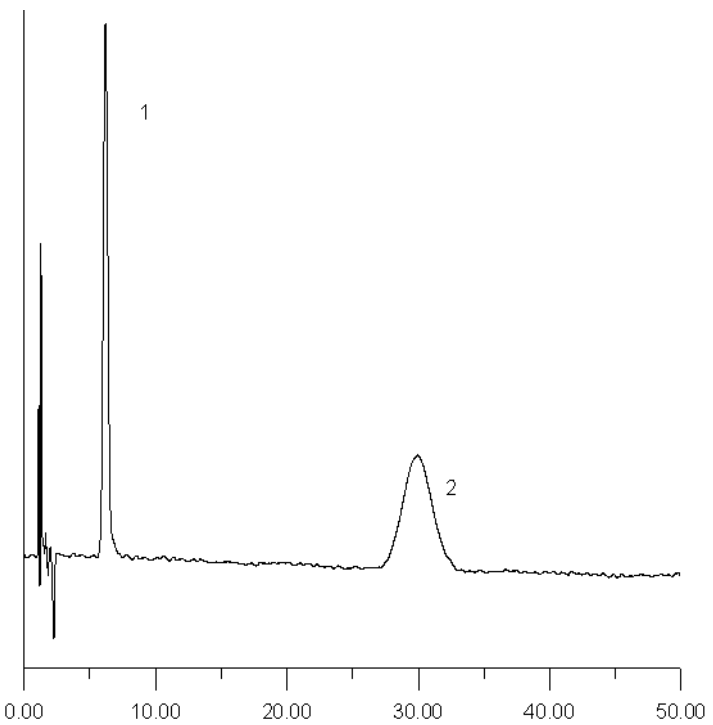

c

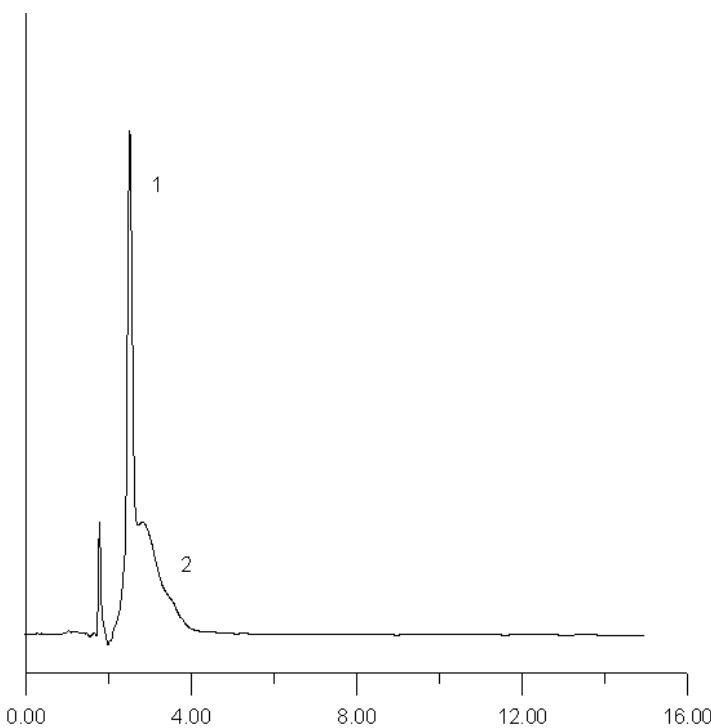

Figure 3. $\mathrm{C}_{18} \quad$ (a), $\mathrm{C}_{8} \quad$ (b) and Cyano (c) chromatograms for amoxicillin (1) and norfloxacin (2). Mobile phase: $0.2 \mathrm{M} \mathrm{SDS}, \mathrm{pH} 3,1 \mathrm{~mL} / \mathrm{min}$. 
Table 1. Physical parameters of the column

\begin{tabular}{clcccc}
\hline $\begin{array}{c}\text { Column } \\
\text { Number }\end{array}$ & Stationary Phase & $\begin{array}{c}\text { Surface } \\
\text { Area }\left(\mathrm{m}^{2} / \mathrm{g}\right)\end{array}$ & $\begin{array}{c}\text { Pore diameter } \\
(\AA)\end{array}$ & $\begin{array}{c}\text { Bonding } \\
\text { nature }\end{array}$ & $\begin{array}{c}\% \mathrm{C} \\
\text { load }\end{array}$ \\
\hline $\mathbf{1}$ & Hipersil - Phenil & 170 & 120 & Phenyl & 5 \\
$\mathbf{2}$ & Kromasil $-\mathrm{NH}_{2}$ & 350 & 100 & Amino & 4.5 \\
$\mathbf{3}$ & Kromasil- $\mathrm{C}_{8}$ & 340 & 100 & $\mathrm{C}_{8}$ & 12 \\
$\mathbf{4}$ & Kromasil $-\mathrm{C}_{18}$ & 340 & 100 & $\mathrm{C}_{18} \mathrm{ec}$ & 19 \\
$\mathbf{5}$ & Zorbax extend $-\mathrm{C}_{18}$ & 180 & 80 & $\mathrm{C}_{18}$ & 20 \\
$\mathbf{6}$ & Nucleosil $-\mathrm{CN}$ & 6 & 100 & $\mathrm{Cyano}$ & 4.5 \\
$\mathbf{7}$ & Chromolith $-\mathrm{C}_{18}$ & 300 & 130 & $\mathrm{C}_{18}$ & 18 \\
\hline
\end{tabular}


Table 2. Tanaka Parameters of the Column

\begin{tabular}{clcccccc}
\hline $\begin{array}{c}\text { Column } \\
\text { Number }\end{array}$ & Stationary Phase & $\mathrm{k}_{\mathrm{PB}}$ & $\alpha_{\mathrm{CH} 2}$ & $\alpha_{\mathrm{T} / \mathrm{O}}$ & $\alpha_{\mathrm{C} / \mathrm{P}}$ & $\begin{array}{c}\alpha_{\mathrm{B} / \mathrm{P}} \\
\mathrm{pH} 7.6\end{array}$ & $\begin{array}{c}\alpha_{\mathrm{B} / \mathrm{P}} \\
\mathrm{pH} 2.7\end{array}$ \\
\hline $\mathbf{1}$ & Hipersil - Phenil & 0.47 & 1.25 & 0.92 & 2.04 & 2.00 & 0.85 \\
$\mathbf{2}$ & Kromasil - NH $\mathrm{N}_{2}$ & -017 & 1.01 & 4.05 & 0.47 & 0.43 & 3.41 \\
$\mathbf{3}$ & Kromasil- $\mathrm{C}_{8}$ & 1.95 & 1.35 & 0.98 & 0.45 & 0.45 & 0.11 \\
$\mathbf{4}$ & Kromasil - $\mathrm{C}_{18}$ & 7.01 & 1.48 & 1.53 & 0.40 & 0.31 & 0.11 \\
$\mathbf{5}$ & Zorbax extend - $\mathrm{C}_{18}$ & 6.66 & 1.50 & 1.49 & 0.38 & 0.20 & 0.08 \\
$\mathbf{6}$ & Nucleosil - CN & 0.19 & 1.10 & 1.5 & 0.78 & 2.01 & 0.26 \\
$\mathbf{7}$ & Chromolith & 4.22 & 1.24 & 1.31 & 0.48 & 0.63 & 0.12 \\
\hline
\end{tabular}

